\title{
O espaço físico como barreira à inclusão escolar ${ }^{1}$
}

\author{
Kênnea Martins Almeida ${ }^{a}$, Viviane dos Reis Lourenço Fernandes ${ }^{b}$, \\ Karolina Alves de Albuquerque ${ }^{c}$, Gibran Ayupe Mota ${ }^{\mathrm{d}}$, Ana Cristina Resende Camargos ${ }^{\mathrm{e}}$ \\ ${ }^{a}$ Curso de Fisioterapia, Universidade Federal do Espírito Santo - UFES, Vitória, ES, Brasil

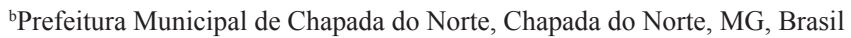 \\ 'Curso de Terapia Ocupacional, Universidade Federal do Espírito Santo - UFES, Vitória, ES, Brasil \\ dPresidência da República, Mata da Praia, Vitória, ES, Brasil \\ ${ }^{\mathrm{e} C u r s o}$ de Fisioterapia, Universidade Federal dos Vales do Jequitinhonha e Mucuri - UFVJM, \\ Diamantina, MG, Brasil
}

\begin{abstract}
Resumo: A arquitetura e a organização dos edifícios escolares podem ser facilitadores ou barreiras na concretização do processo de inclusão escolar, sendo que a avaliação para adequação delas compõe parte importante do papel da equipe de reabilitação nesse processo. O objetivo do estudo foi verificar a acessibilidade física de escolas públicas de uma cidade de Minas Gerais. Foi realizado um estudo descritivo, transversal, com avaliação dos espaços físicos de 14 escolas, especialmente áreas de acesso, circulação e mobiliário, sanitários e estacionamentos, de acordo com os critérios descritos na Norma Brasileira 9050/2004. Os resultados foram apresentados em forma de estatística descritiva. No total foram avaliados 493 itens, desses, 85,6\% encontravam-se inadequados. No setor "Acessos, circulação e mobiliário", $81,4 \%$ dos itens estavam inadequados. No setor "Sanitários", 94,6\% dos itens estavam inadequados, sendo que não foi encontrado nenhum banheiro que contemplasse todas as normas de acessibilidade. No setor "Estacionamentos", 83,4\% dos itens estavam inadequados. Nenhuma escola estadual da cidade estudada encontrava-se preparada para realizar a inclusão escolar de crianças com necessidades especiais no que diz respeito à acessibilidade.
\end{abstract}

Palavras-chave: Educação, Equidade no Acesso, Crianças com Deficiência.

\section{The physical space as a barrier to school inclusion}

\begin{abstract}
The architecture and organization of school buildings can be facilitators or barriers in implementing the process of school inclusion, and the assessment for their suitability composes an important part of the role that the rehabilitation team plays in this process. The aim of the present study was to assess the physical accessibility of public schools in a municipality of Minas Gerais state, Brazil. We conducted a descriptive, cross-sectional study with evaluation of the physical spaces of 14 schools, especially the areas of access, circulation, furniture, restrooms and parking, according to the criteria described in the Brazilian Standard 9050/2004. The results were presented in the form of descriptive statistics. Of the 493 items evaluated, $85.6 \%$ were considered inadequate. In the sector of access, circulation and furniture, $81.4 \%$ of the items were inadequate. In the health sector, $94.6 \%$ of the items were inadequate, and no restrooms contemplating all accessibility standards were found. In the parking sector, $83.4 \%$ of the items were inadequate. It was possible to identify that none of the state schools assessed in the municipality studied is prepared to make the inclusion of children with special needs with regard to accessibility.
\end{abstract}

Keywords: Education, Equity in Access, Disabled Children. 


\section{Introdução}

Entende-se por acessibilidade a

[...] possibilidade e condição de alcance, percepção e entendimento para a utilização com segurança e autonomia de edificaçôes, espaço, mobiliário, equipamento urbano e elementos [...] (ASSOCIAÇÃO..., 2004, p. 2).

A acessibilidade arquitetônica de espaços físicos é essencial para a efetiva participação e autonomia de pessoas com necessidades especiais como deficiências visuais e de locomoção, em diferentes contextos relevantes como casa e escola. A acessibilidade dos ambientes escolares é ainda componente fundamental para a inclusão escolar de crianças com diversas condiçôes de saúde, notadamente aquelas com déficits de mobilidade (MAZZOTA; D'ANTINO, 2011), uma vez que a participação escolar da criança com disfunção depende de sua interaçáo dinâmica e recíproca com o ambiente (PALISANO et al., 2003). A acessibilidade interfere diretamente nas demandas da atividade, mudando as características espaciais e as açôes requeridas para o efetivo desempenho e participaçáo escolar (CAVALCANTI; GALVÃO, 2007).

No Brasil, o direito de crianças com necessidades especiais serem incluídas na escola regular está regulamentado por diversas leis e decretos (BRASIL, 1988, 1996, 2001, 2004; ORGANIZAÇÃO...; MINISTÉRIO..., 2013) e tem fomentado discussóes e trabalhos científicos nas áreas de ensino e saúde em todo o país (LEONARDO; BRAY; ROSSATO, 2009). Com a promulgação da Constituição da República Federativa do Brasil, em 5 de outubro de 1988 (BRASIL, 1988), em face da ampla manifestação advinda dos diversos segmentos da sociedade brasileira, consagraram-se uma série de direitos e garantias voltados à proteçáo de setores até então relegados ao status de "minorias". Nesse contexto, determina a Constituição que o cuidado, proteção e assistência às pessoas com necessidades especiais são de competência da União, dos Estados, do Distrito Federal e dos Municípios (BRASIL, 1988). Diante desse dever que recai sobre os mencionados entes políticos, a efetiva promoção da inclusão escolar manifesta-se como direito inafastável, conforme consta no artigo 208, III, da Constituição Federal:

Art. 208. O dever do Estado com a educação será efetivado mediante a garantia de: III - atendimento educacional especializado aos portadores de deficiência, preferencialmente na rede regular de ensino; [...]

Ainda no âmbito constitucional, a inclusão escolar de crianças com necessidades especiais guarda íntima relação com o Princípio Fundamental da Dignidade da Pessoa Humana, que visa resguardar o valor intrínseco ou ontológico de cada indivíduo enquanto ser humano, independentemente de diferenças de quaisquer ordens (BRASIL, 1988). A inclusão escolar é um processo que impulsiona a transformaçáo do ensino, tornando a escola regular um espaço pluralístico que conjuga igualdade e diferença como valores indissociáveis (BRASIL, 2008; GLAT; FERNANDES, 2005; GLAT; PLETSCH; FONTES, 2006; MARINS; MATSUKURA, 2009; MELO; MARTINS, 2007; MENDES, 2006). É importante que a escola adapte-se aos alunos com necessidades especiais (ANE) e encontre formas de educar com sucesso tais crianças e jovens, independentemente de sua condição física, social ou linguística, ainda que para garantir um ambiente inclusivo seja necessário ultrapassar os seus limites (OLIVEIRA; DRAGO, 2012; ORGANIZAÇÃO...; MINISTÉRIO..., 2013).

No plano infraconstitucional, as leis federais $10.048 / 2000$ e 10.098/2000 estabeleceram de forma pormenorizada normas de acessibilidade para assegurar a integração social, o respeito à dignidade humana e a justiça social, no intuito de possibilitar às pessoas com limitaçóes físicas acesso à educação, saúde, trabalho, lazer, dentre outros (BRASIL, 2004). Com o escopo de regulamentar as leis acima, o decreto 5.296 do ano de 2004 estabelece critérios básicos para garantir a acessibilidade às pessoas com deficiência física, sensorial e intelectual, mobilidade reduzida, idosos, gestantes, obesos e outros, em todos os ambientes públicos (BRASIL, 2004). Com relação ao ambiente escolar, o artigo 29 do referido decreto estabelece:

As escolas e instituiçóes de educação profissional oferecerão, se necessário, serviços de apoio especializado para atender às peculiaridades da pessoa portadora de deficiência, tais como:

$[\ldots]$

III - adequação dos recursos físicos: eliminação de barreiras arquitetônicas, ambientais e de comunicação.

A Associação Brasileira de Normas Técnicas (ABNT) reformulou no mesmo ano (2004), por intermédio do Comitê Brasileiro de Acessibilidade, 
a Norma Brasileira de acessibilidade a edificaçôes, mobiliário, espaços e equipamentos urbanos, denominando-a ABNT NBR 9050/2004 (ASSOCIAÇÃO ..., 2004). Essa norma estabelece parâmetros técnicos de medidas exigíveis para propiciar as mais adequadas condiçóes de acesso a serem observadas no projeto, construção, instalação e adaptação de vias públicas, edificaçóes e mobiliário urbano. O decreto 5.296 de 2004 (BRASIL, 2004) determina que as normas técnicas de acessibilidade da ABNT devem ser seguidas nos ambientes de uso coletivo, a fim de garantir às pessoas com necessidades especiais acesso aos diversos espaços sociais. Tal decreto estabelece ainda que a aprovação de projeto arquitetônico e urbanístico, bem como a execução de qualquer tipo de obra, quando tenham destinação pública ou coletiva, devem obedecer às normas de acessibilidade (BRASIL, 2004). Caso as edificaçóes públicas ou de uso coletivo tenham sido construídas antes de o referido decreto entrar em vigor, as mesmas deveriam obedecer a um prazo de 30 meses, a contar da data de publicação, 3 de dezembro de 2004, para garantir a acessibilidade de pessoas com deficiência ou mobilidade reduzida (BRASIL, 2004). A avaliação sistematizada da acessibilidade, a partir dos critérios estabelecidos pela ABNT NBR 9050/2004, tem sido utilizada na construçáo, reforma e em estudos acerca das condiçôes físicas de espaços públicos (FRANÇA et al., 2010; PAGLIUCA; ARAGÃO; ALMEIDA, 2007).

A inclusão dos ANE, embora determinada pela legislação vigente, ainda encontra obstáculos para sua efetivação. Um dos fatores dificultadores para a efetivação da inclusão escolar refere-se à inadequação da acessibilidade física, que configura uma importante barreira à inclusão educacional de tais crianças (GOMES; BARBOSA, 2006; CORREAA; MANZINI, 2012). Entretanto, outros obstáculos também podem ser destacados, como: insuficiente formação inicial e continuada do professor, resistência dos docentes às mudanças propostas pela política educacional inclusiva, atitudes desfavoráveis dos pais, preconceito por parte dos alunos, carência de materiais básicos e de recursos tecnológicos, número excessivo de alunos por sala, bem como ausência de consenso razoável por parte dos profissionais da área de educação e familiares acerca de sua pertinência (ALMEIDA et al., 2011; BARBOSA; ROSINI; PEREIRA, 2007; CAIXETA; CAMARGOS; ALMEIDA, 2013; CAPELLINI; RODRIGUES, 2009; SILVEIRA; NEVES, 2006).
Em conjunto com profissionais envolvidos na estruturação de espaços de convivência, a equipe de reabilitação, que inclui o terapeuta ocupacional e o fisioterapeuta, pode oferecer uma variedade de alternativas com o intuito de idealizar um ambiente mais adequado à realização de atividades pelo ANE. Essas intervençôes podem ser decisivas no almejado processo de inclusão (MAZZOTA; D’ANTINO, 2011). Dentre diversas possibilidades, Marins e Emmel (2011) citam a remoção de barreiras arquitetônicas, como a substituição de escadas por rampas, adequação de pisos, mobiliário e toaletes, aquisição de materiais pedagógicos e equipamentos específicos para cada aluno. Como a arquitetura e a organizaçáo dos edifícios escolares podem ser facilitadores ou barreiras na concretização do processo de inclusão escolar, a avaliação dos espaços, para sua adequaçáo, compóe parte importante do papel da equipe de reabilitação nesse processo (ALMEIDA et al., 2011; PALISANO et al., 2003).

Dessa forma, este estudo teve por objetivo averiguar a acessibilidade do espaço físico de escolas estaduais de ensino fundamental e médio de uma cidade do estado de Minas Gerais, através dos critérios estipulados pela ABNT NBR 9050/2004 (ASSOCIAÇÃO ..., 2004).

\section{Métodos}

Tratou-se de um estudo transversal, descritivo, no qual foram avaliados os espaços físicos de todas as 14 escolas da rede estadual de ensino fundamental e médio da zona urbana de um município de Minas Gerais. A amostra foi obtida junto à Superintendência Regional de Ensino (SRE) a partir de listagem de todas as escolas da cidade e região. A referida Superintendência aprovou o estudo e emitiu uma carta de recomendaçáo para ser apresentada aos diretores das escolas selecionadas. Na primeira visita às escolas, seus diretores foram informados acerca dos objetivos do estudo, receberam a carta de recomendação da SRE e assinaram a autorização permitindo a avaliação do ambiente físico da escola. Vale ressaltar que esta pesquisa não englobou coleta de dados com sujeitos, apenas espaço físico. Após a aprovação do diretor, cada escola foi visitada novamente por dois pesquisadores deste estudo para a avaliaçáo da sua acessibilidade. $\mathrm{O}$ espaço físico das escolas foi avaliado de acordo com os critérios estabelecidos pela ABNT NBR 9050/2004 (ASSOCIAÇÃO..., 2004). A partir de leitura extensiva de toda a ABNT NBR 9050/2004 foram extraídos 43 itens relevantes de serem avaliados em ambientes 
escolares e construída uma lista de checagem com esses itens. Os itens selecionados dizem respeito, principalmente, ao ambiente interno das edificaçôes e foram transcritos para a lista de checagem exatamente como estão descritos na norma. Essa lista foi desenvolvida por pesquisadores do Núcleo de Acessibilidade e Inclusão (NACI) da Universidade Federal dos Vales do Jequitinhonha e Mucuri (UFVJM) e utilizada também para acompanhamento da adequação dos espaços físicos na construção de um dos seus campus.

Neste estudo, para organização da coleta dos dados e sua análise, os 43 itens da lista de checagem foram subdivididos em três setores: "Acesso, área de circulação e mobiliário"; "Sanitários" e "Estacionamento". No setor "Acesso, circulação e mobiliário" foram verificados 28 itens que dizem respeito a: dimensões mínimas de calçadas e mobiliário; faixas para travessia de pedestres; piso; grelhas; tampas de caixas; entradas de edifícios; sinalização informativa; rampas; escadas; elevadores; corredores; portas; janelas; rotas de fuga; adequação de carteiras; espaço de salas de aula. No setor "Sanitários", a lista de checagem foi composta por nove itens da ABNT NBR 9050/2004 que dizem respeito a: largura de portas; entrada independente; áreas de transferência para cadeira de rodas; barras horizontais; altura dos lavatórios, torneiras, vaso sanitário e espelhos. No setor "Estacionamentos" foram verificados seis itens que dizem respeito a: a sua necessidade; sinalização adequada; barreiras arquitetônicas; obstáculos.

Em cada escola foi verificada a necessidade ou não de aplicação da norma estabelecida para cada um dos 43 itens, sendo avaliados apenas os itens nos quais a norma foi considerada aplicável. Por exemplo, em escolas que apresentavam apenas um piso não houve necessidade de avaliar o item referente a elevadores. Cada item avaliado possibilitou dois resultados: adequado, quando o espaço físico encontrava-se de acordo com as normas, e inadequado, quando o espaço físico náo se encontrava de acordo com as normas estabelecidas para aquele item. A aplicação do instrumento foi realizada por pesquisadores que participaram da construçáo da lista de checagem e fizeram treinamento para sua utilização. Os dados coletados foram inseridos no programa Microsoft Office Excel 2007. Os resultados foram apresentados em forma de estatística descritiva, através de médias e porcentagens das duas respostas: adequado e inadequado.

\section{Resultados e discussão}

Foram avaliadas todas as 14 escolas estaduais da região urbana de um município de Minas Gerais. No total foram considerados aplicáveis e, portanto, avaliados 493 itens nas 14 escolas. Desses, 71 itens $(14,4 \%)$ foram considerados adequados e 422 itens $(85,6 \%)$, inadequados com relação às regras de acessibilidade estabelecidas pela ABNT NBR 9050/2004 (ASSOCIAÇÃO..., 2004). Nenhuma escola apresentou-se totalmente acessível, o que corrobora resultados do estudo de Paulino, Correa e Manzini (2008), que verificaram a acessibilidade física de nove escolas municipais de uma cidade do interior paulista. No presente estudo, a escola que obteve a menor porcentagem de itens adequados $(8,1 \%)$ apresentou resultados inferiores a outros estudos (PAULINO; CORREA; MANZINI, 2008; CORRÊA; MANZINI, 2012). Já a escola que obteve maior porcentagem de itens adequados $(28,6 \%)$ também não apresentou um ambiente físico que permitisse a inclusão plena de um ANE.

$\mathrm{Na}$ Tabela 1 encontram-se os resultados referentes à quantidade e porcentagem de itens adequados e inadequados no setor "Acesso, área de circulação e mobiliário" de todas as escolas. Nesse setor foram avaliados 316 itens, dentre os quais 17\% estavam adequados.

Dentre todas as barreiras sociais e estruturais à inclusão escolar, o acesso físico à entrada da escola parece ser o primeiro desafio arquitetônico que ANE e famílias precisam vencer (DUARTE; COHEN, 2006; RIBEIRO, 2008). No presente estudo, nenhuma escola apresentou entradas acessíveis ou rebaixamento de calçada, sendo a largura das calçadas também inadequada na maior parte das escolas. Esses resultados estão de acordo com os de Duarte e Cohen (2006), que avaliaram dois colégios de aplicação de universidades públicas e identificaram que esses não eram acessíveis, pois apresentavam passeios irregulares e de largura inadequada.

Nenhuma escola do presente estudo apresentou piso regular e antiderrapante, elevador, corrimão nas rampas de acesso aos pisos superiores ou rotas acessíveis, o que pode dificultar para a criança com mobilidade reduzida frequentar todos os ambientes da escola. Outros estudos também têm identificado inadequaçôes nos pisos, rampas, escadas e elevadores de instituiçôes de ensino (DUARTE; COHEN, 2006; LAMÔNICA et al., 2008; PAULINO; CORREA; MANZINI, 2008; RIBEIRO, 2008). Tagliari, Três e Oliveira (2006), em estudo que verificou a acessibilidade de 63 
Tabela 1. Resultado da verificação dos 28 itens do setor "Acessos, área de circulação e mobiliário" das 14 escolas estudadas.

\begin{tabular}{|c|c|c|c|}
\hline & Itens avaliados & $\begin{array}{c}\text { Itens adequados } \\
\mathrm{n}(\%)\end{array}$ & $\begin{array}{c}\text { Itens inadequados } \\
\mathrm{n}(\%)\end{array}$ \\
\hline Entradas acessíveis & 14 & $0(0)$ & $14(100)$ \\
\hline Largura de calçadas & 14 & $4(28,6)$ & $10(71,4)$ \\
\hline Acesso livre de mobiliário nas calçadas & 14 & $12(85,7)$ & $2(14,3)$ \\
\hline Rebaixamento de calçada & 14 & $0(0)$ & $14(100)$ \\
\hline Piso regular e antiderrapante dentro da escola & 14 & $0(0)$ & $14(100)$ \\
\hline Instalação de grelhas & 5 & $0(0)$ & $5(100)$ \\
\hline Piso tátil e direcional & 14 & $0(0)$ & $14(100)$ \\
\hline Instalação de tampas de caixas de inspeção & 11 & $4(28,6)$ & $7(71,4)$ \\
\hline Largura das rampas & 13 & $5(38,5)$ & $8(61,5)$ \\
\hline Sinalização das rampas & 13 & $0(0)$ & $13(100)$ \\
\hline Guias de balizamento nas rampas & 9 & $1(11,1)$ & $8(88,9)$ \\
\hline Patamares das rampas & 13 & $4(30,8)$ & $9(69,2)$ \\
\hline Dimensão de degraus & 14 & $1(7,1)$ & $13(92,9)$ \\
\hline Largura das escadas & 14 & $8(57,1)$ & $6(42,9)$ \\
\hline Patamares das escadas & 7 & $3(42,8)$ & $4(57,2)$ \\
\hline Corrimãos de escadas e rampas & 14 & $0(0)$ & $14(100)$ \\
\hline Guarda-corpo de escadas e rampas & 14 & $5(35,7)$ & $9(64,3)$ \\
\hline Rampas associadas a degraus isolados & 14 & $0(0)$ & $14(100)$ \\
\hline Elevadores & 7 & $0(0)$ & 7 (100) \\
\hline Dimensão de corredores & 14 & $8(57,1)$ & $6(42,9)$ \\
\hline Largura de portas & 14 & $0(0)$ & $14(100)$ \\
\hline Sinalização das portas & 14 & $0(0)$ & $14(100)$ \\
\hline Altura das janelas & 14 & $6(42,8)$ & $8(57,2)$ \\
\hline Rotas de fuga & 14 & $0(0)$ & $14(100)$ \\
\hline Sinalização do espaço físico & 14 & $0(0)$ & $14(100)$ \\
\hline Rotas acessíveis a locais de lazer & 14 & $0(0)$ & $14(100)$ \\
\hline Mesas adaptadas & 14 & $0(0)$ & $14(100)$ \\
\hline Bebedouros & 14 & $0(0)$ & 14(100) \\
\hline Total & 358 & $61(17,0)$ & $255(83,0)$ \\
\hline
\end{tabular}

n: número absoluto.

escolas públicas no Rio Grande do Sul, também levantaram esse problema ao identificarem em apenas uma escola a construção de poço para instalação de um elevador, porém nunca instalado.

A inadequação de rampas e elevadores limita a participação do ANE em diversas atividades escolares relevantes, como aulas de educação física e momentos de recreação que ocorrem em andares distintos do das salas de aula, e pode limitar também crianças pequenas, adultos e idosos que frequentam a escola (PAULINO; CORREA; MANZINI, 2008). Nesse sentido, é importante destacar que grande parte dos ANE que apresentam mobilidade reduzida necessitam utilizar equipamentos de tecnologia assistiva como muletas, bengalas ou cadeiras de rodas. Assim, a ausência ou inadequação de vários itens do instrumento proposto pela ABNT pode limitar, inclusive, o uso de tais recursos. Por exemplo, um aluno que necessita utilizar cadeira de rodas autopropulsionada possivelmente náo conseguirá locomover-se de forma independente dentro da escola porque ela náo oferece rampas adequadas ou elevadores adaptados. As escolas do estudo também não apresentaram rotas de fuga e sinalização do espaço físico, o que prejudica o esvaziamento dos edifícios em caso de incêndios e desmoronamentos, representando risco para toda a comunidade escolar, principalmente para aqueles com dificuldades de locomoção.

Outro aspecto que precisa ser considerado refere-se às dimensóes apropriadas de portas, janelas e corredores. Apesar de mais da metade das escolas do presente estudo ter apresentado dimensões apropriadas dos corredores, nenhuma delas 
apresentou dimensôes adequadas de portas e janelas, o que corrobora resultados encontrados por outros estudos (RIBEIRO, 2008; TAGLIARI; TRÊS; OLIVEIRA, 2006). A inadequação do tamanho das portas dificulta a entrada dos cadeirantes nas salas, bibliotecas, laboratórios de informática e outros setores das escolas, diminuindo as possibilidades de usufruirem os espaços disponíveis para aprendizado e socialização (RIBEIRO, 2008; TAGLIARI; TRÊS; OLIVEIRA, 2006).

É imprescindível que os equipamentos de tecnologia assistiva, dentro das salas de aula, estejam individualmente adaptados para o melhor aproveitamento do educando nas atividades escolares e para sua motivaçáo em permanecer na instituição. No presente estudo, nenhuma das escolas avaliadas apresentava mesas adaptadas. A presença de mesas e cadeiras adaptadas e individualizadas é essencial para manutenção da postura, prevenção de deformidades do sistema músculo-esquelético e adequado rendimento nas atividades visuais e motoras como escrever, o que aprimora o desempenho do ANE na escola (GANANÇA et al., 2008; KAVAK; BUMIN, 2009; RIBEIRO, 2008). Por fim, a ausência de bebedouros acessíveis é outro fator que limita a participação do ANE na escola, pois o torna mais dependente de cuidados que o necessário, se as adaptaçôes existissem (PAULINO; CORREA; MANZINI, 2008; TAGLIARI; TRÊS; OLIVEIRA, 2006).

Os resultados descritivos relacionados ao setor "Sanitários" encontram-se na Tabela 2. Nesse setor foram avaliados 123 itens, dos quais $5,4 \%$ encontravam-se adequados. Náo foram encontradas entradas independentes nem dimensóes que estivessem de acordo com a ABNT
NBR 9050/2004 para portas, barras horizontais para apoio e transferência, torneira, saboneteira, toalheiro, válvula de descarga ou vasos sanitários (ASSOCIAÇÃO..., 2004). Portanto, nenhum sanitário pôde ser considerado acessível, uma vez que é o conjunto desses itens que permite ou não o seu uso pelo ANE. Esse resultado está em consonância com os trabalhos desenvolvidos por Duarte e Cohen (2006) e por Paulino, Correa e Manzini (2008). Durante a coleta de dados deste estudo foi possível observar algumas tentativas de garantir o acesso aos sanitários, como a instalação de barras horizontais, porém elas não obedeciam às normas quanto à altura, número de barras e posicionamento e as portas não permitiam a passagem de cadeira de rodas (Figura 1). Tentativas de se adequar às normas de acessibilidade sem a aplicação restrita das mesmas são comuns em espaços públicos (FRANÇA et al., 2010). Entretanto, essas "falsas soluçôes" podem gerar uma nova forma de exclusão, por não atenderem às reais necessidades dos diferentes usuários do ambiente escolar (MAZZONI et al., 2001).

A análise descritiva do setor "Estacionamentos" está demonstrada na Tabela 3; nela foram considerados adequados $16,6 \%$ dos 12 itens avaliados. A avaliação desse setor foi necessária somente em duas das 14 escolas, porém apenas o item "localização do estacionamento" foi considerado adequado em ambas. Nessas duas escolas que possuíam estacionamento náo foram encontradas vagas para pessoas com necessidades especiais. Tais vagas deveriam estar em locais preestabelecidos, com sinalização adequada, livres de barreiras arquitetônicas e que tivessem comunicação com as demais dependências do prédio (RIBEIRO, 2008). A ausência de estacionamento adequado também

Tabela 2. Resultado da verificação dos nove itens do setor "Sanitários" nas 14 escolas estudadas.

\begin{tabular}{|c|c|c|c|}
\hline & Itens avaliados & $\begin{array}{c}\text { Itens } \\
\text { adequados } \\
\mathrm{n}(\%)\end{array}$ & $\begin{array}{c}\text { Itens } \\
\text { inadequados } \\
\mathrm{n}(\%)\end{array}$ \\
\hline Sanitário acessível & 14 & $0(0)$ & $14(100)$ \\
\hline Dimensão das portas & 14 & $0(0)$ & $14(100)$ \\
\hline Entrada independente & 14 & $0(0)$ & $14(100)$ \\
\hline Área de transferência lateral e frontal ao vaso & 14 & $2(14,3)$ & $12(85,7)$ \\
\hline Barras horizontais para apoio e transferência & 14 & $0(0)$ & $14(100)$ \\
\hline Lavatórios acessíveis & 14 & $2(14,3)$ & $12(85,7)$ \\
\hline Torneira, saboneteira, toalheiro e válvula de descarga & 14 & $0(0)$ & $14(100)$ \\
\hline Vaso acessível & 14 & $0(0)$ & $14(100)$ \\
\hline Espelhos & 11 & $4(36,4)$ & $7(63,6)$ \\
\hline Total & 123 & $8(5,4)$ & $115(94,6)$ \\
\hline
\end{tabular}

n: número absoluto. 
pode dificultar o acesso de outros funcionários à escola, como idosos, gestantes e pessoas com baixa mobilidade.

É importante destacar que o espaço escolar pode ser compreendido como um ambiente social repleto de significados, sendo que a maneira como ele é organizado repercute na dimensão pedagógica e na participação nos diferentes ambientes da escola (ALMEIDA, 2011; ANTUNES, 2008; RIBEIRO, 2008). A mobilidade do ANE depende, dentre outros fatores, da acessibilidade do ambiente. A literatura aponta que crianças com disfunçóes motoras, como
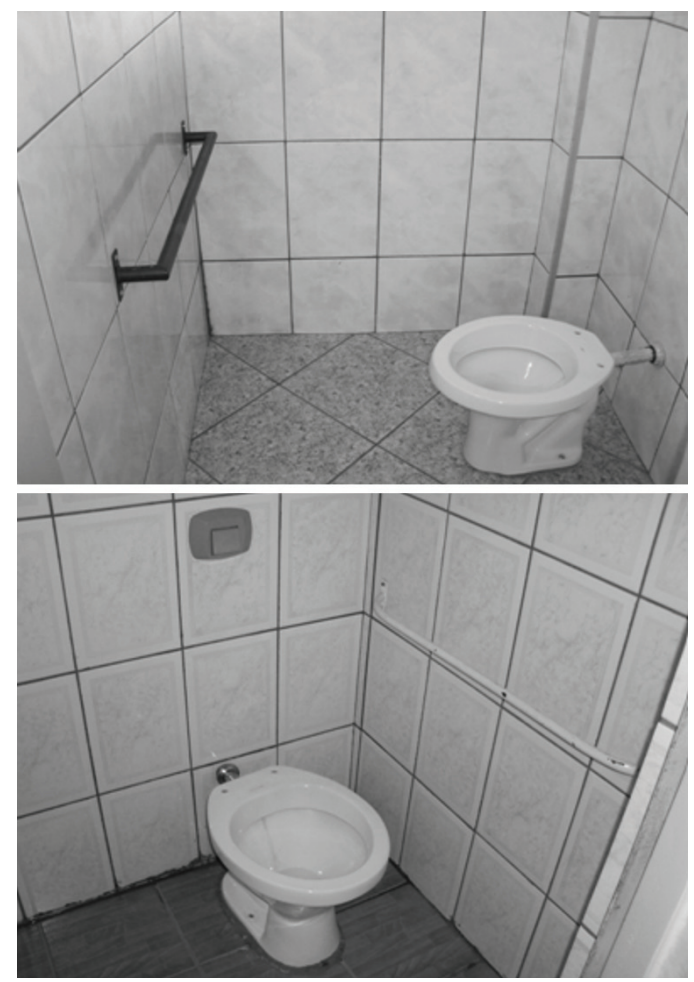

Figura 1. Barras horizontais para apoio e transferência: em cada sanitário foi instalada uma barra, porém tal instalação não obedeceu às normas. é o caso daquelas com paralisia cerebral, apresentam maior limitação de mobilidade dentro da escola e na comunidade, quando comparada com a mobilidade em casa (PALISANO et al., 2003). Além disso, quanto maior o comprometimento da mobilidade, menor a participação na escola (GHEDINI; MANCINI; BRANDÁO, 2010). Dessa forma, as barreiras arquitetônicas tornam o ANE mais dependente, desvalorizam suas potencialidades, dificultam a interação com as demais crianças, isolam e desestimulam a permanência na escola. Em contrapartida, espaços livres de barreiras e acessíveis possibilitam o uso, com segurança e autonomia, de edificaçóes, mobiliários e equipamentos relevantes para o aprendizado e a convivência no ambiente escolar (PAGLIUCA; ARAGÁO; ALMEIDA, 2007).

As escolas avaliadas neste estudo têm, na grande maioria, mais de 10 anos de construção, entretanto, face à legislação vigente, mesmo tendo sido construídas antes da normatização referente à acessibilidade, tais escolas não estariam isentas de se adequarem às normas. A Constituição Federal, ao inaugurar o Título II, sob a insígnia "Dos Direitos e Garantias Fundamentais", e mencionar o termo "garantias", explicita que náo basta prever direitos se esses estiverem dissociados das ações que efetivamente os assegurem, quais sejam, mandados e demais instrumentos jurídicos (BRASIL, 1988). No que se refere ao direito fundamental de acesso universal à educação, no qual a acessibilidade do ANE ao ambiente escolar é componente irrefutável, há uma série de açôes previstas no ordenamento jurídico nacional hábeis a afastar ilegalidades limitadoras de tal direito.

A Lei de Ação Civil Pública (BRASIL, 1985) visa à proteção de interesses difusos ou coletivos, nos quais, indiscutivelmente, insere-se o direito à educaçáo universal e de qualidade. Dentre os legitimados para propor tal ação, destacam-se o Ministério Público, a Defensoria Pública,

Tabela 3. Resultado da verificação dos seis itens do setor "Estacionamentos" nas 14 escolas estudadas.

\begin{tabular}{lccc}
\hline & Itens avaliados & $\begin{array}{c}\text { Itens adequados } \\
\mathbf{n}(\mathbf{\%})\end{array}$ & $\begin{array}{c}\text { Itens inadequados } \\
\mathbf{n}(\mathbf{\%})\end{array}$ \\
\hline Necessita estacionamento adaptado & 2 & $0(0)$ & $2(100)$ \\
Localização dos estacionamentos & 2 & $2(100)$ & $0(0)$ \\
Sinalização dos estacionamentos & 2 & $0(0)$ & $2(100)$ \\
Local das sinalizações & 2 & $0(0)$ & $2(100)$ \\
Barreiras arquitetônicas & 2 & $0(0)$ & $2(100)$ \\
Comunicação com as dependências do serviço & 2 & $0(0)$ & $2(100)$ \\
Total & $\mathbf{1 2}$ & $\mathbf{2}(\mathbf{1 6 , 6})$ & $\mathbf{1 0}(\mathbf{8 3 , 4})$ \\
\hline
\end{tabular}

n: número absoluto. 
demais órgãos públicos dos três entes federados, bem como associaçóes que tenham, dentre suas finalidades institucionais, a proteção de interesses difusos ou coletivos, tais como educação e defesa de deficientes físicos (BRASIL, 1985). Quanto à execução, o trabalho compete a uma equipe especializada, formada por terapeutas ocupacionais, fisioterapeutas, arquitetos e/ou engenheiros, pedagogos e outros profissionais que tenham por intuito, a partir da complementaçáo de conhecimentos, executar práticas e estratégias que permitam ao ANE acesso, possibilidade de permanência e participação efetiva nas propostas sociais e pedagógicas da escola (MARINS; EMMEL, 2011). Um estudo recente identificou as principais açóes desenvolvidas pela Terapia Ocupacional no processo de inclusão escolar de ANE, no estado de São Paulo, e apresentou experiências de contribuições da profissão nesse contexto (CARDOSO; MATSUKURA, 2012). Os resultados apontaram que o sucesso das intervençōes de terapeutas ocupacionais, no processo de inclusão escolar, está relacionado principalmente às ações desempenhadas na escola regular, dentre as quais se destacam a orientação de professores e a orientação para adequação/adaptação de espaços físicos e recursos materiais (CARDOSO; MATSUKURA, 2012). Considerando-se o escopo deste trabalho, os órgãos públicos, bem como os profissionais especializados, podem e devem ser instados a agir no sentido de remover barreiras, físicas ou não, que impeçam a acessibilidade do ANE nas escolas públicas ou privadas.

\section{Conclusão}

Este estudo averiguou a acessibilidade física de escolas estaduais da zona urbana de um município de Minas Gerais utilizando como parâmetro de avaliação os critérios estabelecidos pela ABNT NBR 9050/2004 (ASSOCIAÇÃO..., 2004). De acordo com os resultados desta pesquisa, foi possível identificar que nenhuma escola estadual da cidade onde a pesquisa foi realizada encontrava-se preparada para a inclusão escolar de alunos com necessidades especiais no que diz respeito à acessibilidade do espaço físico.

\section{Referências}

ASSOCIAÇÃO BRASILEIRA DE NORMAS TÉCNICAS - ABNT. NBR - 9050: Norma de acessibilidade e edificações, mobiliário, espaços e equipamentos urbanos. Rio de Janeiro, 2004.
ALMEIDA, G. C. et al. Barreiras e facilitadores no processo de inclusão de crianças com paralisia cerebral em escolas de ensino regular. Cadernos de Terapia Ocupacional, São Carlos, v. 19, n. 2, p. 203-213, 2011.

ANTUNES, K. C. V. Uma leitura crítica da construção do espaço escolar à luz do paradigma da inclusão. InterMeio: revista do Programa de Pós-Graduaçáo em Educaçáo, Campo Grande, v. 14, n. 28, p. 188-203, 2008.

BARBOSA, A. J. G.; ROSINI, D. C.; PEREIRA, A. A. Atitudes parentais em relaçáo à educaçáo inclusiva parental. Revista Brasileira de Educação Especial, Marília, v. 13, n. 3, p. 447-458, 2007.

BRASIL. Constituição da República Federativa do Brasil de 1988. Diário Oficial da República Federativa do Brasil, Brasília, DF, 5 out. 1988. Disponível em: $<$ http://www.planalto.gov.br/ccivil_03/constituicao/ constitui\%C3\%A7ao.htm>. Acesso em: 20 out. 2013.

BRASIL. Decreto No 5.296, de 2 de dezembro de 2004. Regulamenta as Leis ${ }^{\text {os }} 10.048$, de 8 de novembro de 2000 , que dá prioridade de atendimento às pessoas que especifica, e 10.098, de 19 de dezembro de 2000, que estabelece normas gerais e critérios básicos para a promoção da acessibilidade das pessoas portadoras de deficiência ou com mobilidade reduzida, e dá outras providências. Diário Oficial da República Federativa do Brasil, Brasília, DF, 3 dez. 2004. Disponível em: <http:// www.planalto.gov.br/ccivil_03/_ato2004-2006/2004/ decreto/d5296.htm>. Acesso em: 15 out. 2013.

BRASIL. Lei $N^{\circ} 7.347$, de 24 de julho de 1985. Disciplina a ação civil pública de responsabilidade por danos causados ao meio-ambiente, ao consumidor, a bens e direitos de valor artístico, estético, histórico, turístico e paisagístico (VETADO) e dá outras providências. Diário Oficial da República Federativa do Brasil, Brasília, DF, 25 jul. 1985. Disponível em: <http://www.planalto.gov.br/ ccivil_03/leis/17347orig.htm>. Acesso em: 21 nov. 2013.

BRASIL. Lei No 10.172, de 9 de janeiro de 2001. Aprova o Plano Nacional de Educação e dá outras providências. Diário Oficial da República Federativa do Brasil, Brasília, DF, 10 jan. 2001. Disponível em: <http://www.planalto. gov.br/ccivil_03/leis/leis_2001/110172.htm>. Acesso em: 15 out. 2013.

BRASIL. Lei No 9.394, de 20 de dezembro de 1996. Estabelece as diretrizes e bases da educação nacional. Diário Oficial da República Federativa do Brasil, Brasília, DF, 23 dez. 1996. Disponível em: <http://www.planalto. gov.br/ccivil_03/Leis/L9394.htm>. Acesso em: 15 out. 2013.

BRASIL. Politica Nacional de Educação Especial na Perspectiva da Educação Inclusiva. Brasília, DF: MEC, 2008. Disponível em: <http://portal.mec.gov.br/ arquivos/pdf/politicaeducespecial.pdf $>$. Acesso em: 15 out. 2013.

CAIXETA, M. O.; CAMARGOS, A. C. R.; ALMEIDA, K. M. A inclusão escolar em uma cidade do Vale do Jequitinhonha-MG. Temas sobre Desenvolvimento, São Paulo, v. 19, n. 105, p. 147-152, 2013. 
CAPELLINI, V. L. M.; RODRIGUES, O. M. R. Concepçáo de professores acerca dos fatores que dificultam o processo da educação inclusiva. Revista Educação, Porto Alegre, v. 32, n. 3, p. 355-364, 2009.

CARdoso, P. T.; MATSUKURA, T. S. Práticas e perspectivas da terapia ocupacional na inclusão escolar. Revista de Terapia Ocupacional da USP, Sáo Paulo, v. 23, n. 1, p. 7-15, 2012.

CAVALCANTI, A.; GALVÃO, C. Adaptação Ambiental e Doméstica. In: CAVALCANTI, A.; GALVÃO, C. (Orgs.). Terapia Ocupacional: fundamentação \& prática. Rio de Janeiro: Guanabara Koogan, 2007. p. 295-298.

CORREAA, P. M.; MANZINI, E. J. Um estudo sobre as condiçóes de acessibilidade em pré-escolas. Revista Brasileira de Educação Especial, Marília, v. 18, n. 2, p. 213-230, 2012.

DUARTE, C. R. S.; COHEN, R. Proposta de metodologia de avaliaçáo da acessibilidade aos espaços de ensino fundamental. In: SEMINÁRIO INTERNACIONAL NUTAU 2006: DEMANDAS SOCIAIS, INOVAÇÓES TECNOLÓGICAS E A CIDADE, 2006, São Paulo. Anais ... São Paulo: USP: 2006. p. 1-12.

FRANÇA, I. S. X. et al. Violência simbólica no acesso das pessoas com deficiência às unidades básicas de saúde. Revista Brasileira de Enfermagem, Brasília, v. 63, n. 6, p. 964-970, 2010. http://dx.doi.org/10.1590/ S0034-71672010000600015

GANANÇA, A. S. et al. Assento adaptável para portadores de paralisia cerebral e seqüela de escoliose: estudo de caso aplicando design ergonômico. Revista Fisioterapia e Movimento, Curitiba, v. 21, n. 4, p. 51-61, 2008.

GHEDINI, L. S. L.; MANCINI, M. C.; BRANDÃO, M. Participação de alunos com deficiência física no contexto da escola regular: Revisão de Literatura. Revista de Terapia Ocupacional da USP, Sáo Paulo, v. 21, n. 1, p. 1-9, 2010.

GLAT, R.; FERNANDES, E. M. Da educação segregada à educaçáo inclusiva: uma breve reflexão sobre os paradigmas educacionais no contexto da educação especial brasileira. Revista Inclusão, São Paulo, n. 1, out. 2005. Disponível em: <http://portal.mec.gov.br/ seesp/arquivos/pdf/revistainclusaol.pdf $>$. Acesso em: 15 set. 2012.

GLAT, R.; PLETSCH, M. D.; FONTES, R. S . Uma breve reflexão sobre o papel da educação especial frente ao processo de inclusão de pessoas com necessidades educacionais especiais em rede regular de ensino. Revista Inclusão Social, Rio de Janeiro, n. 6, p. 13-33, 2006.

GOMES, C.; BARBOSA, A. J. G. Inclusão escolar do portador de paralisia cerebral: atitudes de professores do ensino fundamental. Revista Brasileira de Educaçäo Especial, Marília, v. 12, n. 1, p. 85-100, 2006.

KAVAK, S. T.; BUMIN, G. Os efeitos da postura de pega do lápis e de diferentes modelos de mesa sobre o desempenho na caligrafia de crianças com paralisia cerebral hemiplégica. Jornal de Pediatria, Rio de Janeiro, v. 85, n. 4, p. 346-352, 2009.

LAMÔNICA, D. A. C. et al. Acessibilidade em ambiente universitário: identificação de barreiras arquitetônicas no campus da USP de Bauru. Revista Brasileira de Educação Especial, Marília, v.14, n. 2, p. 177-188, 2008.

LEONARDO, N. S. T.; BRAY, C. T.; ROSSATO, S. P. M. Inclusão escolar: um estudo acerca da implantação da proposta em escolas de ensino básico. Revista Brasileira de Educação Especial, Marília, v. 15, n. 2, p. 289-306, 2009. MARINS, S. C. F.; EMMEL, M. L. G. Formação do Terapeuta Ocupacional: Acessibilidade e Tecnologias. Cadernos de Terapia Ocupacional da UFSCar, São Carlos, v.19, n. 1, p. 37-52, 2011.

MARINS, S. C. F.; MATSUKURA, T. S. Avaliação de políticas públicas: a inclusão de alunos com necessidades educacionais especiais no ensino fundamental das cidades-pólos do estado de São Paulo. Revista Brasileira de Educação Especial, Marília, v.15, n. 1, p. 45-64, 2009.

MAZZONI, A. A. et al. Aspectos que interferem na construçáo da acessibilidade em bibliotecas universitárias. Ciência da Informação, Brasília, v. 30, n. 2, p. 29-34, 2001.

MAZZOTA, M. J. S.; D’ANTINO, M. E. F. Inclusão social de pessoas com deficiências e necessidades especiais: cultura, educação e lazer. Revista Saúde e Sociedade, São Paulo, v. 20, n. 2, p. 377-389, 2011. http:// dx.doi.org/10.1590/S0104-12902011000200010

MELO, F. R. L. V.; MARTINS, L. A. R. Acolhendo e atuando com alunos que apresentam paralisia cerebral na classe regular: a organização da escola. Revista Brasileira de Educação Especial, Marília, v.13, n. 1, p.11-130, 2007.

MENDES, E. G. A radicalização do debate sobre inclusão escolar no Brasil. Revista Brasileira de Educação, Rio de Janeiro, v.11, n. 33, p. 397-405, 2006.

OLIVEIRA, A. A. S.; DRAGO, S. L. S. A gestão da inclusáo escolar na rede municipal de Sáo Paulo: algumas considerações sobre o Programa Inclui. Ensaio: Avaliação e Políticas Públicas em Educação, Rio de Janeiro, v. 20, n. 75, p. 347-372, 2012.

PAGLIUCA, L. M. F.; ARAGÃO, A. E. A.; ALMEIDA, P. C. Acessibilidade e deficiência física: identificação de barreiras arquitetônicas em áreas internas de hospitais de Sobral, Ceará. Revista da Escola de Enfermagem, São Paulo, v. 41, n. 4, p. 581-588, 2007.

PALISANO, R. J. et al. Effect of environmental setting on mobility methods of children with cerebral palsy. Developmental Medicine \& Child Neurology, Massachusetts, v. 45, p. 113-120, 2003. http://dx.doi. org/10.1111/j.1469-8749.2003.tb00914

PAULINO, V. C.; CORREA, P. M.; MANZINI, E. J. Um estudo sobre a acessibilidade física em nove escolas municipais do ensino fundamental de uma cidade do interior paulista. Revista de Iniciação Científica da Faculdade de Filosofia e Ciência, Marília, v. 8, n. 1, p. 59-74, 2008.

RIBEIRO, S. L. A interface acessibilidade e educação inclusiva. Revista InterMeio: Revista do Programa de 
Pós-Graduação em Educação, Campo Grande, v. 13, n. 27, p.118-128, 2008.

SILVEIRA, F. F.; NEVES, M. M. B. Inclusão escolar de crianças com deficiência múltipla: concepções de pais e professores. Revista Psicologia: Teoria e Pesquisa, Brasília, v. 22, n. 1, p. 79-88, 2006.

TAGLIARI, C.; TRÊS, F.; OLIVEIRA, S. G. Análise da acessibilidade dos portadores de deficiência física nas escolas da rede pública de Passo Fundo e o papel do fisioterapeuta no ambiente escolar. Revista Neurociências, São Paulo, v. 14, n. 1, p.10-14, 2006.
ORGANIZAÇÃO DAS NAÇÓES UNIDAS PARA A EDUCAÇÁO, A CIÊNCIA E A CULTURA - UNESCO; MINISTÉRIO DA EDUCAÇÃO E CIÊNCIA. Declaração de Salamanca: sobre princípios, políticas e práticas na área de necessidades educativas especiais. Espanha, 2013. Conferência Mundial sobre Necessidades Educativas Especiais: Acesso e Qualidade. Salamanca, Espanha, 7-10 de junho de 1994. Disponível em: <http://portal. mec.gov.br/seesp/arquivos/pdf/salamanca.pdf $>$. Acesso em: 10 out. 2013.

\section{Contribuição dos Autores}

Kênnea Martins Almeida: Colaborou com o planejamento do estudo, redação e revisão do texto. Viviane dos Reis Lourenço Fernandes: Colaborou com a coleta dos dados e redação do texto. Karolina Alves de Albuquerque: Colaborou com a redação e revisão do texto. Gibran Ayupe Mota: Colaborou com a redação e revisão do texto. Ana Cristina Resende Camargos: Colaborou com o planejamento do estudo e revisão do texto. Todos os autores aprovaram a versão final do texto.

\section{Notas}

${ }^{1}$ Trata-se de estudo que não realizou coleta de dados com sujeitos, apenas em espaço físico. Parte dos resultados deste trabalho foi apresentada no evento VII Semana de Fisioterapia da Universidade Federal dos Vales do Jequitinhonha e Mucuri - UFVJM, em formato de pôster, no ano de 2010. 